\title{
Perencanaan Fasilitas Pariwisata di Desa Wisata Kerta, Kecamatan Payangan,Kabupaten Gianyar,Bali
}

I Putu Arnawa Suputra a,1 I Made Adikampana a,2

${ }^{1}$ suputra_arnawa@gmail.com 2adikampana@unud.ac.id

a Program Studi Sarjana Destinasi Pariwisata, Fakultas Pariwisata, Universitas Udayana, Jl. Dr. R. Goris, Denpasar, Bali 80232 Indonesia

\section{Abstract}

The tourism development has led to changes in land use, social and ecnomic aspects. As the new flagship sector of Kerta Tourism Village which is one of the village's clans designated as a tourist village in accordaance with Gianyar Regent Decree Number 429/E-02/HK in 2017on Payangan District, Gianyar Regency. So in developing the potential that must be with the planning of tourism facilities match to the Tourism Village Kerta condition.

The research study uses descriptive qualitative analysis method with data collection tehniques such as observation, interview, documentation and literature study. The technique of data analysists used are reduction data, presentation data, and conclusion/verification. The determining technique of informant are using tehnique of purposive sampling, this research is limited by using tourism destination life cycle theory, tourism planning concept, facility concept, tourism village, concept, and tourism product component.

The result of the research is that Kerta Tourism Village is currently in the phase of involvement, of local communities in the development and planning of tourism facilities in Kerta Tourism Village. It can be seen from the existence of tourism facilities that are still not optimal such as communications, electricity, restaurant, roads, wantilan, parking area, heatlh facilities and bins.

Keywords : Tourism Planning, Facilities, Tourism Products and Village Tours.

\section{PENDAHULUAN}

Pariwisata merupakan industri yang saat kini diunggulkan bagi negara-negara di dunia serta diharapkan dapat mendorong perekonomian. Sebagai suatu sektor peluang kehidupan baru, seperti di Indonesia yang terdapat potensi wilayah sangat beragam. Sekaligus lengkap dengan destinasi wisata yang memiliki ciri khas potensi alam, aneka warisan budaya, dan sejarah yang telah mengambil peran penting dalam pembangunan perekonomian dunia, khususnya ditujukan untuk meningkatkan kesejahteraan ekonomi maupun kehidupan masyarakat setempat.

Perubahan dalam penggunaan lahan, aspek sosial dan ekonomi merupakan dampak dari adanya perkembangan pariwisata. Diperkuat dengan adanya keberadaan daya tarik wisata yang mempengaruhi kondisi wilayah dan masyarakat sekitar. Upaya pengembangan pariwisata yang dilakukan pada setiap daerah di Indonesia, sebagai salah satu sektor penggerak dalam meningkatkan peluang ekonomi baru yang diharapkan mampu dimanfaatkan oleh masyarakat setempat, seperti contohnya wisatawan mancanegara yang sudah mengenal destinasidestinasi wisata di Pulau Bali serta terkenal akan pesona seribu pura.
Menurut Undang-Undang Republik Indonesia Nomor 10 Tahun 2009. Tentang Kepariwisataan yang tercantum pada Bab I pasal 1 ayat 6 disebutkan bahwa Daerah tujuan pariwisata yang selanjutnya disebut sebagai Destinasi pariwisat merupakan kawasan geografis yang berada dalam satu atau lebih wilayah administratif yang di dalamnya terdapat daya tarik wisata, fasilitas umum, fasilitas pariwisata, aksessibilitas serta masyarakat yang saling terkait dan melengkapi terwujudnya kepariwisataan. Sehingga, Desa Wisata Kerta menjadi salah satu daftar daerah tujuan destinasi pariwisata baru yang seharusnya layak wisatawan dikunjungi yang kini harus didukung dengan perencanaan fasilitas pariwisata yang memadai sebagai sarana pokok penunjang menarik minat wisatawan yang berkunjung ke Desa Wisata Kerta.

Salah satu contoh kegiatan pariwisata yang kini sedang gencarnya dikembangkan oleh Bali bagian tengah. Yaitu Kabupaten Gianyar, khusunya di Desa Wisata Kerta, Kecamatan Payangan menjadi salah satu daya tarik unggulan dimana upaya pengembangan yang dilakukan setiap daerah bervariatif dengan pengembangan pariwisata secara terintegrasi pertanian agrowisata. Agar ada dampak langsung ekonomi dari kegiatan 
pariwisata kepada masyarakat di desa sebagai suatu komunitas desa adat.

Perkembangan sangat signifikan dapat dilihat dari banyaknya kedatangan wisatawan ke Gianyar dari bulan januari hingga mei total kunjungan wisatawan yaitu 2.27.491 wisatawan asing (Disparda Kabupaten Gianyar, 2017). Tentu jumlah wisatawan yang datang sangat berdampak ke desa wisata khusunya ke Desa Wisata Kerta yang terletak pada jantung kecamatan Payangan ini, tentunya harus didukung oleh perencanaan fasilitas pariwisata yang baik agar wisatawan yang berkunjung merasakan kepuasan dan tidak merasa kecewa akan berkunjung ke daerah wisata. Desa Wisata Kerta banyak memiliki potensi yang menarik untuk dikembangkan, hanya saja karena minimnya pengetahuan tentang tata cara perencanaan fasilitas pariwisata. Sehingga sinergitas masyarakat lokal kurang mengerti tentang cara ikut berpartisipassi dalam mengembangkan fasilitas apa saja yang harus dibangun di sekitar Desa Wisata Kerta, meningkatnya perkembangan pada industri pariwisata menjadi tantangan baru dalam memberikan rasa nyaman dan aman akan berkunjung sehingga mendapatkan fasilitas yang sangat baik di tempat destinasi yang dikunjungi, sudah seharusnya masyarakat ataupun pengelola desa memberikan fasilitas yang mumpuni dan memberikan jaminan kenyamanan melalaui upaya perencanaan fasilitas pariwisata kepada wisatawan. Sehingga kondisi Desa Wisata Kerta sangat menarik untuk dikaji tentang Perencanaan Fasilitas Pariwisata Di Desa Wisata Kerta, Kecamatan Payangan, Kabupaten Gianyar, Bali.

\section{KEPUSTAKAAN}

\subsection{Tinjauan Penelitian Sebelumnya}

Penelitian ini merujuk pada beberapa jurnal terkait dengan fokus dan lokus penelitian ini, rujukan penelitian yang pertama adalah "Perencanaan Fasilitas Pariwisata (Tourism Amenities) Pantai Pandawa, Desa Kutuh, Kuta Selatan, Badung" oleh Putu Shintani Utari dan I Made Adi Kampana tahun, 2014. Penelitian ini memperoleh hasil bahwa faktor yang mempengaruhi perencanaan fasilitas pariwisata adalah banyak hal salah satunya ialah kurangnya rambu rambu atau arah penunjuk jalan ke tempat suatu daya tarik wisata, selain itu kurangnya fasiitas yang mendukung seperti tempat sampah, toilet dan penerangan yang kurang memadai. Oleh karena hal tersebut sangat berimplikasi terhadap ketidaknyamanan kepada wisatawan yang berkunjung ke Pantai Pandawa. Selain itu rendahnya pengetahuan masyarakat lokal terhadap sadar wisata yang berdampak kepada kebersihan dan keindahan Pantai Pandawa.

Penelitian kedua adalah sebuah penelitian yang berjudul "Perencanaan Fasilitas Pariwisata Di Kampung Wae Rebo, Desa Satarlenda, Kabupaten Manggarai Tengah, Nusa Tenggara Timur" oleh Andryano Febrian Bambar tahun, 2015. Penelitian ini memperoleh hasil bahwa perencanaan fasilitas pariwisata di Kampung Wae Rebo masih belum maksimal dibuktikan dengan masih kurangnya fasilitas pendukung seperti toilet, papan penunjuk arah, penginapan serta restaurant yang berada di kampung tersebut selain itu, Fokus pada penelitian ini yaitu merencanakan fasilitas-fasilitas pariwisata khusunya yang berhubungan dengan wisata alam, serta mengembangkan fasilitas pendukung pariwisata yang sudah ada di Kampung Wae Rebo.

Dalam artikel ini menggunakan beberapa teori dan konsep diantaranya teori siklus hidup destinasi wisata (Butler, 1998), Konsep Perencanaan Pariwisata (Gunn, 1998), Konsep Desa Wisata (Hadiwijoyo, 2012), Komponen Produk Pariwisata (4A) (Cooper dalam Ariyanto, 2005),

Perencanaan merupakan serangkaian proses secara sistematis yang terdiri dari kegiatan untuk mencapai tujuan tertentu. Sedangkan fasilitas merupakan sarana maupun prasarana dalam melengkapi keperluan utama wisatawan, seperti: tempat penginapan, tempat makan, restoran, tempat parkir dan kamar mandi. Sehingga dapat dipahami bahwa perencanaan fasilitas yang dimaksudkan dalam penelitian ini yaitu perencanaan fasilitas pariwisata yang lebih 
memberikan arahan pengembangan fasilitas di Desa Wisata Kerta.

\section{METODE PENELITIAN}

Penelitian ini mengambil lokasi di Desa Wisata Kerta, Kecamatan Payangan, Kabupaten Gianyar, Provinsi Bali yang terletak di daerah dataran tinggi sekitar dua jam waktu tempuh dari Bandara I Gusti Ngurah Rai sekitar 70 km. Lokasi peneliitian ini ditetapkan sebagai Desa Pusat Pertumbuhan (DPP) di kawasan Agropolitan Payangan Kabupaten Gianyar berdasarkan keputusan Bupati Gianyar nomor 194 tahun 2003.

Teknik pengumpulan data dalam penelitian ini menggunakan teknik observasi, wawancara dan dokumentasi untuk menemukan data primer berupa kondisi eksisting Desa yang dapat dikembangkan sehingga dapat ditentukan perencanaan pariwisata ke arah mana yang tepat dilakukan untuk mengelola Desa Wisata Kerta. Selain teknik observasi, wawancara, dan dokumentasi peneliti juga menggunakan teknik studi kepustakaan yang digunakan dalam mendukung penelitian ini melalui penelusuran dokumen penelitian sebelumnya yang tentunya memiliki permasalahan sejenis.

Pada teknik analisis data dalam penelitian ini yaitu analisis deskriptif kualitatif. Teknik analisis data ini dimulai dari proses reduksi data yaitu meliputi mencatat dan mengumpulkan informasi mengenai aspek perencanaan fasilitas pariwisata, penyajian data yang meliputi fasilitas apa saja yang telah ada akan tetapi belum maksimal dan fasilitas baruapa saja yang akan dibangun dan verifikasi/kesimpulan meliputi menyocokkan data yang didapat dilapangan serta mengklasifikasi kemudian menarik kesimpulan umum pada penelitian mengenai perencanaan fasilitas pariwisata.

\section{HASIL DAN PEMBAHASAN}

\subsection{Letak, Kondisi Wilayah Dan Demografi Desa Wisata Kerta}

Desa Kerta merupakan satu dari sembilan Desa wisata yang ada di Kecamatan Payangan, Kabupaten Gianyar yang berbatasan langsung dengan Kecamatan Kintamani Kabupaten Bangli. Desa Kerta memiliki wilayah seluas $\pm 1442,3$ hektar atau $14,23 \mathrm{~km}^{2}$.
Luas tersebut terbagi menjadi delapan Banjar Dinas/Adat dan delapan Desa Pekraman.

\subsection{Kondisi Eksisting Desa Wisata Kerta}

Kondisi eksisting yang terdapat di Desa Wisata Kerta dilihat dari model siklus hidup destinasi wisata yang sedang dialami dari Desa Wisata Kerta sudah jelas terlihat berada pada tahapan kedua saat yaitu fase involment (keterlibatan). Pada fase ini, Desa Wisata Kerta yang sebagian masyarakat lokal mulai menyediakan fasilitas pariwisata untuk wisatawan, seiring meningkatnya jumlah kunjungan serta mulai adanya promosi akan tetapi kontak antara wisatawan dan masyarakat lokal masih rendah sehingga masyarakat lokal mulai mengubah pola-pola sosial yang ada untuk merespon perubahan ekonomi yang terjadi di kehidupan masyarakat Desa Wisata Kerta.

Komponen produk pariwisata Desa Wisata Kerta, Kecamatan Payangan, Gianyar terdiri atas 4 komponen utama (4A) yaitu:

a. Attraction (daya tarik wisata)

Atraksi yang terdapat di Desa Wisata Kerta terbagi berdasarkan potensi yang dimiliki saat ini diantaranya: Daya tarik wisata yang dimaksudkan adalah pemandangan alam yang dimiliki oleh Desa Wisata Kerta meliputi pemandangan pohon bambu, pemandangan sawah serta kegiatan perkebunan. Daya tarik buatan di Desa Wisata Kerta yaitu potensi yang sengaja dibuat untuk wisatawan sebagai atraksi di Desa Wisata Kerta meliputi wisata trecking dari pura puncak sari sampai bumi perkemahan, cycling yairu mulai dari banjar marga ke banjar seming, wisata selfie serta camping di bumi perkemahan.

Daya tarik budaya yaitu kondisi sosial budaya masyarakat ataupun peninggalan seperti kuburan batu dikenal dengan sarkofagus, tarian rejang pingitan.

b. Amenities (fasilitas)

Prasarana dan sarana yang diperlukan oleh wisatawan selama berada di daerah tujuan wisata seperti homestay dari rumah penduduk, villa montana dan villa air terjun, restaurant, rumah makan, tempat parkir. 
c. Accesibility (aksesibilitas)

Jalan masuk atau pintu masuk utama ke daerah tujuan wisata yang mendukung kegiatan kepariwisataan serta dalam mendukung dari adanya Program Pembangunan Infrastruktur Pertanian (PPIP) tentunya, dalam kaitan dengan kegiatan pariwisata di Desa Wisaa Kerta akses yang menjadi penghubung ke Kintamani, Kabupaten Bangli. Namun jalan memasuki tergolong rusak dikarenakan terdapat jalan yang masih berlubang-lubang sehingga menggangu kenyamanan pengunjung sebelum memasuki Bumi perkemahan serta ke munduk asri.

d. Ancillary services (pelayanan tambahan).

Pelayanan tambahan tentunya faktor yang sangat penting serta merupakan sarana pelengkap yang harus disediakan dari suatu daerah tujuan wisata, baik untuk wisatawan maupun untuk pelaku pariwisata. Sehingga diharapkan dapat memberikan rasa aman dan nyaman dalam berkunjung ke Desa Wisata Kerta. Pelayanan tambahan seperti Gazebo Munduk Asri, Wantilan menyerupai di bumi perkemahan, satu buah dapur dan dan area tempat berfoto.
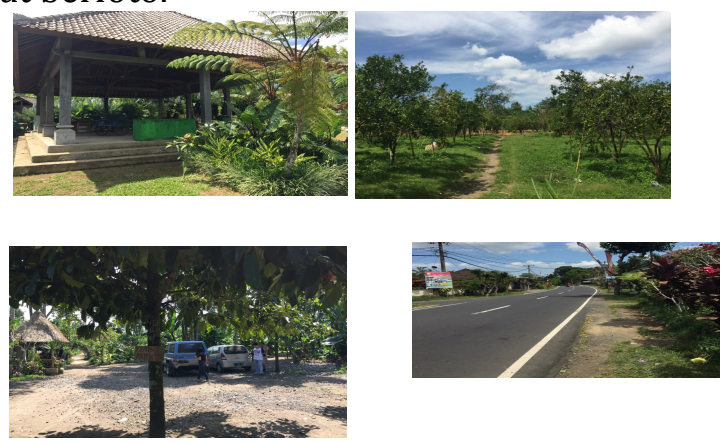

\section{Gambar 4.2 Kondisi Eksisting Desa} Wisata Kerta

Sumber: Dokumentasi Penelitian, Mei 2018

\subsection{Perencanaan Fasilitas Pariwisata Di Desa Wisata Kerta, Kecamatan Payangan, Kabupaten Gianyar}

Perencanaan fasilitas pariwisata yang dimaksud dalam penelitian ini adalah Perencanaan fasilitas pariwisata yang lebih memberikan arahan pengembangan fasilitas di Desa Wisata Kerta yang ditinjau dari:

a. Perbaikan fasilitas eksisting yang sudah ada di Desa Wisata Kerta meliputi:

1. Komunikasi dan listrik di Desa Wisata Kerta, standar minimal tersebut yang sudah terpenuhi yakni warga menggunakanTV dalam kesehariannya termasuk di villa tempat wisatawan menginap. lalu untuk radio juga sudah ada di desa wisata kerta, sinyal telephone juga sudah cukup baik. penjual voucher atau isi ulang pulsa juga sudah ada. Untuk internet akses di desa wisata kerta juga sudah cukup terpenuhi dengan baik dengan sinyal 4G. Akan tetapi untuk listrik, sebagai penerangan jalan di Desa Wisata Kerta msih belum cukup baik dikarenakan masih minimnya terdapat tiang-tiang listrik di sisi jalan.

2. Rumah makan, masih kurangnya tempat makan yang memiliki papan nama, tempat parkir sehingga belum terlihat kesiapan pengelola untuk menata rapi rumah makan yang disediakan guna untuk menarik wisatawan yang berkunjung ke Desa Wisata Kerta.

3. Jalan, ketika memasuki daerah Bumi Perkemahan Pucak Sari masih terbilang ada yang rusak dan juga masih kurangnya pembatas jalan, rambu rawan bencana hingga arah penunjuk jalan itupun masih kurang.

4. Wantilan, Dalam penataan wantilan yang terdapat di Bumi Perkemahan tentunya masih dalam tahap pembangunan sekitar $75 \%$.

5. Tempat parkir, kurangnya pengoptimalan dari segi tatanan agar terlihat lebih rapi dan menarik sehingga para wisatawan baik yang membawa kendaraan pribadi.

6. Fasilitas kesehatan, diperlukannya dokter maupun perawat yang bisa berbahasa asing sehingga lebih memudahkan dalam berkomunikasi dengan wisatawan.

7. Tempat sampah, masih terbilang sangat minim ditemui di setiap Desa Wisata Kerta sehingga perlunya penambahan untuk menjaga kebersihan lingkungan.

b. Pembangunan fasilitas baru di Desa Wisata Kerta meliputi:

1. Homestay, perencanaan ke depan di Desa Wisata Kerta dengan memanfaatkan rumah masyarakat setempat diharapkan dapat menambah nilai jual kepada wisatawan yang lebih mengedepankan interaksi sosial.

2. Penambahan gazebo akan dilakukan pembangunan lagi kurang lebih sekitar 2 hingga 3 gazebo guna memfasilitasi para wisatawan yang berkunjung. 
Selain itu gazebo juga akan dibangun di titik-titik pemberhentian trekking.

3. Toilet, berdasarkan dari hasil wawancara yang di lakukan dengan ketua bumdes, pengelola Munduk Asri dan Kepala Desa tentunya hal yang sama di katakan mengenai penambahan pembangunan toilet sebagai sarana pelengkap guna untuk mengimbangi banyaknya wisatawan yang berkunjung.

4. Tenda, Penambahan fasilitas camping seperti tenda akan dilakukan di Bumi Perkemahan ini hal ini disampaikan oleh ketua bumdes yang mengatakan saat ini hanya memiliki 10 tenda dengan kapasitas 70 orang, sehingga kedepannya akan memaksimalkan tenda.

Berikut merupakan hasil penelitian dari klasifikasi perencanaan fasilitas pariwisata di Desa Wisata Kerta.

Matrik 1

Klasifikasi Perencanaan Fasilitas Pariwisata Di Desa Wisata Kerta

\begin{tabular}{|l|l|}
\hline \multicolumn{1}{|c|}{$\begin{array}{c}\text { Perbaikan Fasilitas } \\
\text { Eksisting }\end{array}$} & \multicolumn{1}{|c|}{$\begin{array}{c}\text { Pembangunan } \\
\text { Fasilitas Baru }\end{array}$} \\
\hline $\begin{array}{l}\text { 1. Komunikasi dan } \\
\text { Listrik }\end{array}$ & $\begin{array}{l}\text { 1. Homestay } \\
\text { 2. Gazebo }\end{array}$ \\
2. Rumah Makan & 3. Toilet \\
3. Jalan & 4. Tenda \\
4. Wantilan & \\
5. Tempat Parkir & \\
6. Fasilitas Kesehatan & \\
7. Tempat Sampah & \\
\hline
\end{tabular}

Sumber: Hasil Penelitian, 2018

\section{SIMPULAN DAN SARAN}

\section{a. Simpulan}

Dari penelitian yang telah dilakukan diperolehlah beberapa simpulan yang dapat disampaikan sebagai hasil dari penelitian ini. Simpulan-Simpulan yang dapat disampaikan tersebut diantaranya adalah:

a. Kondisi eksisting Desa Wisata Kerta ditinjau dari Teori Siklus Hidup Destinasi

Wisata (Destination Lifecycle) dan Komponen Produk Pariwisata, diantaranya:

1. Jika dilihat berdasarkan Teori Siklus Hidup Destinasi Wisata (Destination Lifecycle) tentunya Desa Wisata Kerta kini berada pada fase ataupun tahapan pengembangan pariwisata sudah jelas terlihat berada pada tahapan kedua saat yaitu fase involment (keterlibatan).

2. Kondisi eksisting Desa Wisata Kerta, Kecamatan Payangan, Gianyar ditinjau dari komponen produk pariwisata yang harus ada untuk mendukung suatu Destinasi Wisata terdiri atas 4 (empat) komponen utama (4A) yaitu: Daya Tarik Wisata yang ada di Desa Wisata Kerta yaitu: Pemandangan alam, Wisata trekking ataupun cycling, Wisata Selfie di Munduk asri, Sarkofagus serta Tempat rekreasi camping di Bumi Perkemahan Pucak Sari. Untuk fasilitas yang ada di Desa Wisata Kerta diantaranya: homestay, villa, rumah makan, tempat parkir, toilet, air bersih, komunikasi dan listrik dan fasilitas kesehatan. Sedangkan untuk aksesibilitas yang terdapat di Desa Wisata Kerta sudah cukup baik, dan sering dilalui dengan transportasi darat seperti, mobil pribadi, travel dan motor. Selanjutnya Fasilitas Pendukung yang ada di Desa Wisata Kerta saat ini diantaranya Gazebo, Wantilan dan Tempat berfoto.

b. Adapun perencanaan fasilitas pariwisata di Desa Wisata Kerta, Kecamatan Payangan, Gianyar yang ditinjau dari:

1. Fasilitas yang sudah ada, tetapi masih belum optimal ataupun tidak berfungsi dengan baik di Desa Wisata Kerta diantaranya seperti: komunikasi dan listrik listrik, rumah makan, jalan, wantilan, tempat parkir, fasilitas kesehatan, dan tempat sampah.

2. Pembangunan fasilitas baru apa saja yang akan dikembangkan untuk mencapai strategi ataupun program yang telah direncanakan seperti: homestay, gazebo, toilet, dan tenda.

\section{b. Saran}

Adapun beberapa saran yang dapat disampaikan guna menjadi referensi beberapa pihak:

1. Kepada Pemerintah

Pemerintah sebagai fasilitator dalam hal ini diharapkan untuk memberikan pengarahan dan sosialisasi secara terpadu terkait langkah-langkah awal untuk 
merencanakan fasilitas pariwisata apa saja yang cocok di bangun di Desa Kerta sebagai Desa Wisata, pemerintah juga diharapkan memberikan bantuan dana dalam pengoperasian prasana, selain itu aparatur desa juga diharapkan membantu mempromosikan Desa Wisata Kerta sehingga ketanggapan aparatur desa akan hal tersebut nantinya dapat segera terealisasikan dalam waktu dekat dalam upaya pembangunan fasilitas pariwisata di Desa Wisata Kerta.

\section{Kepada Pengelola}

Pengelola diharapkan mampu mengembangkan potensi-potensi yang sudah dimiliki menjadi 3 jenis daya tarik alam,buatan dan budaya sekaligus disesuaikan dengan perencanaan pengembangan fasilitas baru yang tepat dengan menggunakan pendekatan Enviromental and suistainable development approach, sehingga masyarakat juga diharapkan ikut terlibat dalam perencanaan fasilitas pariwisata tanpa merusak ekosistem yang ada di Desa Wisata Kerta

3. Kepada Masyarakat lokal

Masyarakat Desa Wisata Kerta diharapkan mampu menjaga potensi yang dimiliki saat ini, tanpa mengekploitasi berlebihan yang dapat menyebabkan kerusakan lingkungan, alih fungsi lahan terhadap pembangunan, sehingga diperlukannya pemahaman yang mendalam mengenai perencanaan fasilitas pariwisata apa saja yang seharusnya tepat di bangun guna memajukan kegiatan pariwisata di Desa Wisata Kerta

\section{DAFTAR PUSTAKA}

Anonim, 2009. Undang-Undang RI No.10 Tahun 2009 Tentang Kepariwisataan.

Bambar, Andryano Febryan, and Andryano Febrian Bambar. 2015. "Perencanaan Fasilitas Pariwisata Di Kampung Wae Rebo, Desa Satarlenda, Kabupaten Manggarai Tengah, Nusa Tenggara Timur. Diss", Universitas Udayana.

Budiasa I Made. 2009. "Analisis Perencanaan strategis Daya Tarik Wisata Bali Orchid Garden".Program Pascasarjana Universitas Udayana.Denpasar.

Butler. R.W, 1998. "The Concept of a Tourist Area Cycle of Evolution: Implications For Management of Resources". University of Western Ontario.

Clarke, J \& Godfrey K. 2000. The Tourism Development Handbook: A Practical Approach To Planning and Marketing. Continuum, London.
Cooper, Chris, 2011. Essentials of Tourism. Oxford:Prentice Hall.

Gunn, Clare A. 1988. "Tourism Planning". Taylor \& Francis Publishing.

Hadiwijoyo,SuryoS.2012."PerencanaanPariwisataPerdesa anBerbasisMasyarakat(SebuahPendekatan Konsep)"1sted.,GrahaIlmu, Yogyakarta.

Inskeep, Edward, 1998. Guide for local Authorities on Developing Sustainable Tourism. World Tourism Organization, New York

Kusmayadi dan Sugiarto, Endar. 2000. Metodologi Penelitian dalam Bidang Kepariwisataan. Jakarta : PT. Gramedia Pustaka Utama.

Maswarita Mery, 2010. Teori Perencanaan. Teori Perencanaan / Pertama / 11540(2).htm.

Paturusi, S A,2008. "Perencanaan kawasan pariwisata." Denpasar: Universitas Udayana.

Pitana, I Gde dan I Ketut Surya Diarta. 2009. Pengantar Ilmu Pariwisata. Yogyakarta: ANDI

Sugiyono. 2014. Metode Penelitian Manajemen. Bandung: Alfabeta

Utari, Putu Shintani, and I. Made Adikampana, 2014. "Perencanaan Fasilitas Pariwisata (Tourism Amenities) Pantai Pandawa Desa Kutuh Kuta Selatan Badung." Jurnal Destinasi Pariwisata: 5767.

Yoeti, Oka A, 1982. Pengantar Ilmu Pariwisata. Pengertian Pariwisata. Bandung. Angkasa.

Yulianie, Fatrisia. 2015. Partisipasi Dan Pemberdayaan Masyarakat Dalam Pengelolaan Daya Tarik Wisata "Rice Terrace" Ceking, Gianyar, Bali. Jurnal Master Pariwisata (JUMPA). Vol 2 No 1: Hal 165184. 